\title{
Panel urges caution on genetic testing for mental disorders
}

[LONDON] Britain's main bioethics advisory panel has issued a strong warning against attempts to use genetic screening to predict an individual's susceptibility to common mental health disorders such as schizophrenia and Alzheimer's disease.

Aware that companies may soon be tempted to offer 'over the counter' tests for such diseases, based on the identification of susceptibility genes, the panel suggests that regulations could be needed to replace the voluntary constraints now in force.

But it also says that, in view of the potential importance of genetic studies in treating such diseases, there should be no bar on using people who are mentally incapacitated as research subjects, provided that this is carried out with "the appropriate safeguards".

The conclusions come in a report published this week by a working party of the Nuffield Council on Bioethics, the body set up in 1991 as Britain's national forum for identifying ethical questions raised by advances in biological and medical research.

The report, Mental disorders and genetics: the ethical context, says there has been great progress in recent years in refining genetic tests for those relatively rare diseases, such as Huntington's disease and fragile X syndrome, which are generally known to be due to a defect in a single gene. In such cases, it says, tests have a high predictive value clearly relevant to decisions about treatment.

It also points out that researchers working on more complex diseases have frequently identified genetic mutations associated with these diseases, even if almost every such locus is still the subject of scientific controversy. Indeed, the report says that the difficulty of identifying reproducible gene localizations in common mental diseases "represents a key scientific discovery in its own right".

But the working party, which was chaired by Dame Fiona Caldicott, principal of Somerville College, Oxford, and immediate past president of the Royal College of Psychiatrists, warns against over-hasty attempts to use the success of screening tests for singlegene diseases as a basis for promoting the likely value of tests for the others.

In a letter to Nature (see page 317), the members of the working party say that, even if a number of susceptibility genes were identified for a particular disorder, "without an understanding of their interaction, they would not be adequate for predicting individual risk in a clinical setting".

Their report identifies Alzheimer's dis- ease in particular as a case in which, even though there is good evidence of linkage to a particular allele of the apolipoprotein $\mathrm{E}$ gene, the clinical and predictive value of this knowledge remains low because other, unknown factors are likely to be involved.

"For such diseases, people may want to look for [genetic mutations] because it may be useful in helping us understand the disease," says working party member Martin Richards, director of the Centre for Family Studies at the University of Cambridge. "But as a public health measure, we see no future in that type of testing in the near future."

Committee members admit that there was a spectrum of views on the long-term potential of genetic tests for multifactorial diseases. "I would be a little more optimistic than some," says Peter McGuffin, professor of psychological medicine at the University of Wales.

But McGuffin, who will shortly become director of the Medical Research Council's Social, Genetic and Developmental Psychiatry Research Centre, also says that disagreement tended to be on scientific grounds rather than over ethical principles.

The Nuffield report is likely to set the framework for more detailed discussion of technical developments by bodies such as the Advisory Committee on Genetic Testing. It sets its face firmly against "geneticization", which it describes as "an increasing tendency" on the part of some researchers "to view human beings essentially as gene carriers".

It also says that predictive genetic testing and testing for carrier status for mental disorders in children should "be strongly discouraged", and that testing in adoption cases "raises important and complex issues which require appropriate guidance".

And it argues that the present voluntary system of approval for directly marketed tests "is likely to prove insufficient", suggesting that if monitoring of the marketing of such tests and the use of their results shows up adverse consequences, the UK government should seek to impose national or international regulation of such tests.

The main thrust of the report is likely to be endorsed by many of those concerned with the welfare of individuals suffering from genetic diseases.

"I am very glad someone has drawn attention to the difference between the situation facing those at risk from single-gene diseases and multifactorial genetic diseases," says Alistair Kent, director of the Genetic Interest Group. "The single-gene model has served people well, but is not necessarily the way in which we should approach more complex diseases."

DavidDickson
[WASHINGTON] An advocacy group is challenging two proposed in utero gene-therapy experiments due to be discussed today (24 September) and tomorrow by the Recombinant DNA Advisory Committee (RAC) of the National Institutes of Health.

In a letter sent to the RAC last week, the Boston-based Council for Responsible Genetics charges that the in utero method, proposed by gene-therapy pioneer French Anderson, professor of biochemistry and paediatrics at the University of Southern California School of Medicine, leads "farther down the slippery slope to eugenics".

But Anderson said on Monday that the council's criticism was "welcome", and that, while he judges the risk of germline modification in his experiments to be minute, he has submitted his proposals "in order to have a public debate".

In the council's letter to the RAC, Wendy McGoodwin, its executive director, warns that the proposed experiments risk making modifications to the fetal germ line that would be passed on to succeeding generations.

The RAC currently refuses to consider proposals aimed at modifying the germ line. The Anderson proposals do not seek to do this, but inadvertent germline modification is an admitted risk of in utero therapy. McGoodwin urges the committee "to tell Dr
Anderson that the RAC does not consider in utero gene therapy to be an acceptable subject for research".

The letter is among 70 pages of public comments, most of them negative, that the RAC has received in response to a public notice of the meeting.

Of Anderson's in utero proposals, one aims to treat $\alpha$-thalassaemia, an error of haemoglobin synthesis, and the other severe combined immunodeficiency caused by adenosine deaminase deficiency (see Nature 395, 8; 1998). Neither protocol is ready for use in humans. At least two years of vector development and animal studies are necessary first, says Anderson. Meredith Wadman 